\title{
Observations of greenhouse gases as climate indicators
}

\author{
Lori Bruhwiler $^{1}$ (D) - Sourish Basu ${ }^{2,3}$ (D) - James H. Butler ${ }^{1}$ (D) $\cdot$ \\ Abhishek Chatterjee $^{2,3}$ (D) Ed Dlugokencky $^{1}$ (D) Melissa A. Kenney ${ }^{4}$ (D) \\ Allison McComiskey ${ }^{5}$ (D) Stephen A. Montzka ${ }^{1}$ (D) Diane Stanitski ${ }^{1}$ (D)
}

Received: 6 August 2020 / Accepted: 13 January 2021 / Published online: 8 March 2021

(C) This is a U.S. government work and not under copyright protection in the U.S.; foreign copyright protection may apply 2021

\begin{abstract}
Humans have significantly altered the energy balance of the Earth's climate system mainly not only by extracting and burning fossil fuels but also by altering the biosphere and using halocarbons. The 3rd US National Climate Assessment pointed to a need for a system of indicators of climate and global change based on long-term data that could be used to support assessments and this led to the development of the National Climate Indicators System (NCIS). Here we identify a representative set of key atmospheric indicators of changes in atmospheric radiative forcing due to greenhouse gases (GHGs), and we evaluate atmospheric composition measurements, including non- $\mathrm{CO}_{2}$ GHGs for use as climate change indicators in support of the US National Climate Assessment. GHG abundances and their changes over time can provide valuable information on the success of climate mitigation policies, as well as insights into possible carbon-climate feedback processes that may ultimately affect the success of those policies. To ensure that reliable information for assessing GHG emission changes can be provided on policy-relevant scales, expanded observational efforts are needed. Furthermore, the ability to detect trends resulting from changing emissions requires a commitment to supporting longterm observations. Long-term measurements of greenhouse gases, aerosols, and clouds and related climate indicators used with a dimming/brightening index could provide a foundation for quantifying forcing and its attribution and reducing error in existing indicators that do not account for complicated cloud processes.
\end{abstract}

Keywords Greenhouse gases · Radiative forcing · Anthropogenic emissions · Atmospheric composition

This article is part of a topical collection on "National Indicators of Climate Changes, Impacts, and Vulnerability" edited by Melissa A. Kenney and Anthony C. Janetos.

Lori Bruhwiler

lori.bruhwiler@noaa.gov

Extended author information available on the last page of the article 


\section{Introduction}

Humans have significantly perturbed the energy balance of the climate system mainly not only by extracting and burning fossil fuels but also through land use changes and halocarbon usage. Agriculture and waste treatment also release nitrous oxide and methane to the atmosphere, and both are strong greenhouse gases (GHGs). In response to anthropogenic GHG emissions, the global atmosphere has warmed over the last half century. By 2017, global mean surface temperature (GMST) was found to be about $1{ }^{\circ} \mathrm{C}$ above preindustrial values and increasing at $0.2^{\circ} \mathrm{C} /$ decade (Allen et al. 2018). This trend is slightly higher (4-8\%) if global mean surface air temperature (GSAT) rather than blended air and sea surface temperature is considered (Cowtan et al. 2015; Richardson et al. 2018).

Understanding changes in atmospheric composition is essential for estimating changes in the energy balance of the atmosphere. Quantifying exchanges of GHGs among the biosphere, oceans, and atmosphere as well as anthropogenic emissions can also be useful indicators of global change but are more difficult to quantify. Time-dependent emission estimates are crucial for evaluating success of emission reduction strategies, and identifying trends in natural exchange processes can further understanding of how natural processes respond to climate change.

The 3rd US National Climate Assessment pointed to a need for a system of indicators of climate and global change based on long-term data that could be used to support assessments (Corell et al. 2014). Kenney et al. (2014, 2016) described development and prototypes of such a system, the National Climate Indicators System (NCIS), to establish a "system of physical, natural, and societal indicators that communicate and inform decisions about key aspects of the physical climate, climate impacts, vulnerabilities, and preparedness." Its primary purpose is to support the sustained US National Climate Assessment (Buizer et al. 2013) by providing longterm information that is regularly updated and comparative to a baseline of change. Indicators are reference tools that can be constructed from measured data, modeled data, or an index and they can facilitate advancement and communication of scientific understanding, inform decision-making, and demonstrate progress in achieving management objectives. Indicators relevant to key US systems and sectors, such as indicators for the atmosphere including greenhouse gases, are required by the 1990 Global Change Research Act and are of broad concern to the US public (see Kenney et al. 2018, this issue). A proof-of-concept indicator system was released by the US Global Change Research Program in 2015 (http://www. globalchange.gov/explore/indicators) and included Annual Greenhouse Gas Index (AGGI) and Atmospheric Carbon Dioxide indicators. This paper revisits and expands on the conceptual model for these indicators.

Observations of atmospheric greenhouse gases are useful climate indicators because they can be used to show the influence of human activities (e.g., emissions) on the climate system. Carbon dioxide $\left(\mathrm{CO}_{2}\right)$ is included in USGCRP Climate Indicators, while atmospheric burdens of methane $\left(\mathrm{CH}_{4}\right)$, nitrous oxide $\left(\mathrm{N}_{2} \mathrm{O}\right)$, synthetic ozone depleting gases, and other long-lived halogenated gases and their changes over time (including over the past 800,000 years) are included in the EPA's set of key climate indicators. Both the EPA and the USGCRP emphasize the utility of climate indicators for communication about changing climate, environmental assessment, and informed decision-making. A related effort is the collection of Essential Climate Variables (ECVs) identified by the World Meteorological Organization (WMO, https://public.wmo.int/en/programmes/global-climate-observing-system/essentialclimate-variables). The criteria for ECVs include how critical a variable is for characterizing 
the changing climate system, and whether it is feasible and cost effective to observe that particular variable. The WMO also defines a set of climate monitoring principles that lay out needs for continuity and compatibility of data sets, data management, maintenance of longterm measurements, and focus on under-observed regions.

The objective of this paper is to identify a representative set of key atmospheric indicators of changes in atmospheric radiative forcing driven by greenhouse gases. In particular, we evaluate the use of atmospheric composition measurements as climate change indicators. We present a conceptual model of climate forcing used to identify potential indicators (Section 2), the proposed key indicators (Sections 3, 4, and 5), and research and indicator development opportunities (Section 6). Such indicators provide an overview of the climate forcing that causes the climate impacts and vulnerabilities, and, when tracked over time, can be a measure of large-scale mitigation response effectiveness.

Global surface temperature change is an essential indicator of changing climate, and climate change policies have targeted limits in global temperature increase relative to the pre-industrial era. The recognition of an approximate linear relationship between cumulative $\mathrm{CO}_{2}$ emissions and temperature increase has allowed for estimation of remaining $\mathrm{CO}_{2}$ emissions consistent with temperature change targets (Allen et al. 2009; Gregory et al. 2009; Matthews et al. 2009). Clearly, observational records from which global atmospheric burdens of $\mathrm{CO}_{2}$ can be deduced provide an important link between cumulative emissions, which could be considered climate indicators, and global temperature change. Such observations allow confirmation of the linear relationship (Gillett et al. 2013) and could be useful for detecting departures from the linear relationship between cumulative emissions and temperature change if feedback processes become significant.

Non- $\mathrm{CO}_{2}$ climate forcers or short-lived climate pollutants (SLCPs), such as $\mathrm{CH}_{4}, \mathrm{~N}_{2} \mathrm{O}$, and manufactured halogenated gases, complicate the simple connection between cumulative $\mathrm{CO}_{2}$ emissions and temperature. Some SLCPs have lifetimes as short as a decade, implying that the effects of emissions at a particular time will not significantly influence temperatures decades later. On the other hand, some short-lived climate pollutants (SLCPs) are much more effective at trapping heat in the climate system than $\mathrm{CO}_{2}$ so that reducing their emissions could provide short term benefit. It may also be economically advantageous to reduce SCLP emissions. For example, fugitive emissions of $\mathrm{CH}_{4}$ from oil and gas production have economic value. For policy considerations, it is useful to have metrics that allow tradeoffs between $\mathrm{CO}_{2}$ and SCLP emissions to be evaluated; however, incorporating SLCPs into cumulative carbon budgets is difficult due to the range and uncertainties of atmospheric lifetimes. Metrics designed to provide simple quantifications of the joint effects of SLCPs and $\mathrm{CO}_{2}$ emissions on atmospheric radiative forcing range from looking at GWPs and GTPs over short- and long-time horizons, to using simple or medium complexity models to estimate climate-relevant equivalence between SLCP and $\mathrm{CO}_{2}$ emissions (Tanaka et al. 2010, 2019; Jenkins et al. 2018; Cain et al. 2019; Collins et al. 2020). Observational records of the global abundances of SLCPs are essential for computing and evaluating these metrics.

\section{A conceptual model of climate forcing indicators}

Kenney et al. (2018, this issue) point to the need for a conceptual model to justify climate indicators. A conceptual model is communicated by a simple diagram that shows how a complex system functions, and measurable quantities that can be used to characterize 
important components of the system. Figure 1 shows a conceptual model of atmospheric composition climate indicators. Radiative forcing is the quantity that needs to be quantified over time, and in Section 4, we describe how it can be estimated using observations of major GHGs and used as a climate indicator. We also propose that atmospheric concentrations of major non- $\mathrm{CO}_{2}$ GHGs are indicators of changes in anthropogenic and natural sources and sinks. Atmospheric concentrations of GHGs underlay radiative forcing estimates and change over time due to anthropogenic emissions and natural processes that regulate exchanges of these gases among atmosphere, terrestrial biosphere, and oceans (Section 3). Many SLCPs are also removed in the atmosphere by chemical or photolytic loss.

Information about fluxes, if constrained by observable quantities and updated over time, could also be useful indicators (Section 5). Additional indicators could be identified to quantify observed changes in radiative fluxes at the Earth's surface as a foundation for understanding the role of GHGs versus the impacts of changing aerosol and cloud distributions due to changes in both emissions (aerosol) and changes in atmospheric circulations (clouds) from natural and anthropogenic processes. These future climate indicators would be more difficult to quantify and would involve the use of models, process level measurements, and inventories of emissions. As such, use of these quantities as possible future climate indicators is still an active area of research.

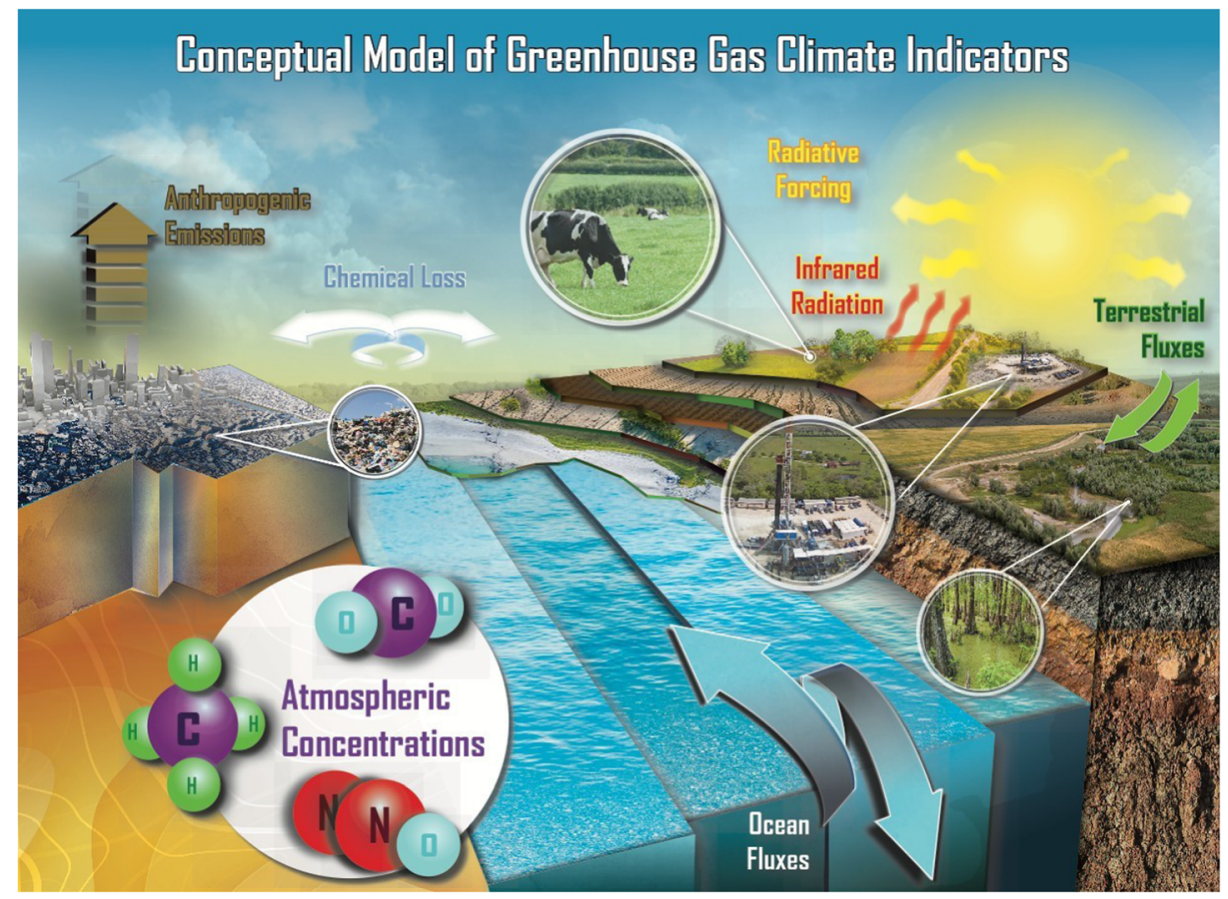

Fig. 1 Conceptual model for greenhouse gas (GHG) climate indicators. Indicators proposed in this study are atmospheric concentrations of non- $\mathrm{CO}_{2} \mathrm{GHGs}\left(\mathrm{CO}_{2}\right.$ is already included in the National Climate Indicator System (NCIS)). Atmospheric GHG concentrations are directly observable and can be monitored over time. They can also be used to estimate radiative forcing. The Annual Greenhouse Gas Index (AGGI) is also included in the NCIS and quantifies the change in radiative forcing due to GHGs relative to 1990. Solid arrows indicate sources and sinks of atmospheric GHGs. Observations constraining these processes could be useful future climate indicators, but fluxes of GHGs are at present difficult to quantify at large spatial and temporal scales 


\subsection{Atmospheric measurements of radiatively active atmospheric constituents as climate indicators}

In this section, we review the role of major GHGs in climate forcing. We discuss the role of emission inventories for anthropogenic sources and point out their value as climate indicators. Long-term observational records of major greenhouse gases are essential for evaluating bottom-up understanding of emissions and for evaluating the effectiveness of mitigation policies (Canadell et al. 2010). Figure 2 shows observations of major greenhouse gases and how they have changed over time.

The strong greenhouse gas sulfur hexafluoride $\left(\mathrm{SF}_{6}\right)$, a manufactured gas that is used as an electrical insulator, provides an instructive example of the importance of atmospheric measurements. Emissions of $\mathrm{SF}_{6}$ reported to the UNFCCC (which includes only Annex 1 Countries) were found by Rigby et al. (2010) to be much lower than those derived using global atmospheric observations of $\mathrm{SF}_{6}$. Monitoring atmospheric concentrations of greenhouse gases is essential as an evidence-based, independent method for assessing the effects of strategies to reduce emissions.

\subsection{Emission inventories: the "bottom-up" approach}

The framework of using indicators to measure progress towards emission and sustainable development goals has long been employed by the emission inventory community. For example, the UNEP Economics and Trade Unit developed a standardized methodology for estimating GHG emissions from companies and other organizations (Thomas et al. 2000). The California Air
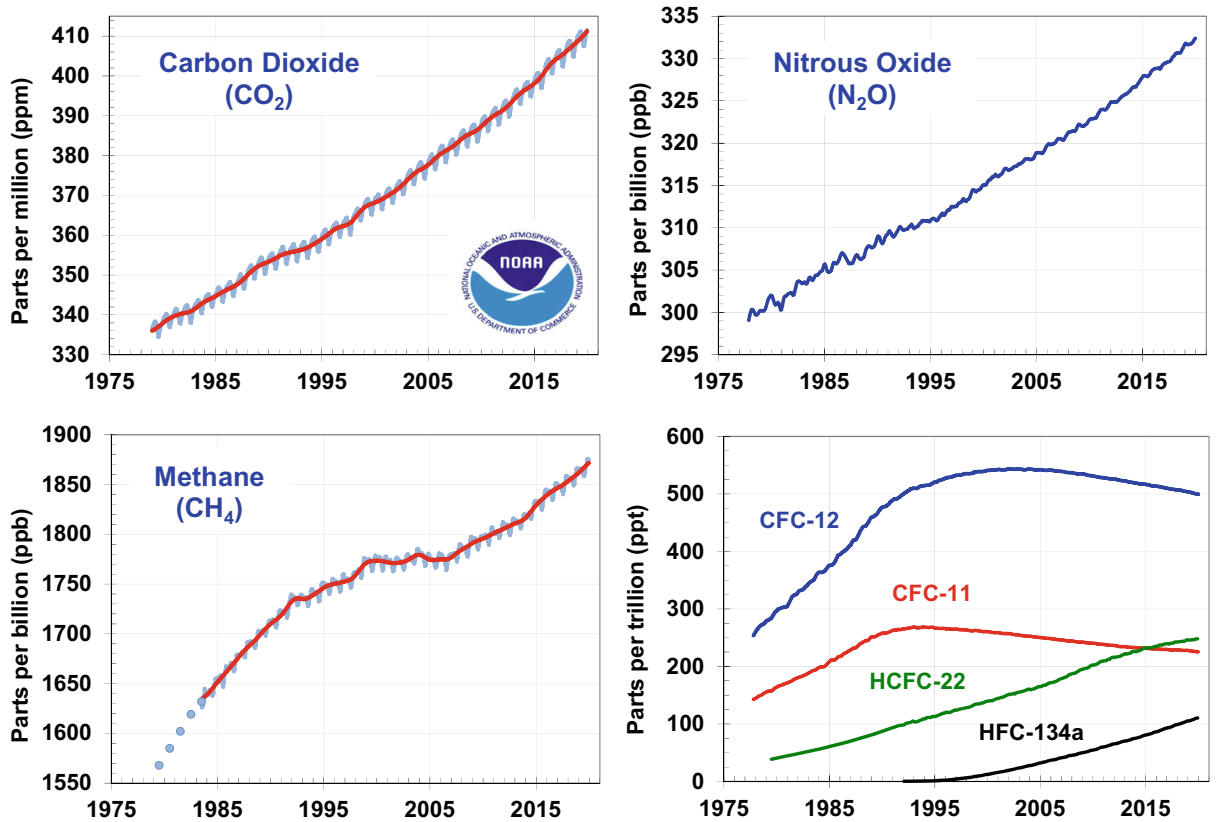

Fig. 2 Global average abundances of the major, well-mixed, long-lived greenhouse gases - carbon dioxide, methane, nitrous oxide, CFC-12, and CFC-11 - from the NOAA global air sampling network are plotted since the beginning of 1979 
Resources Board produces ongoing report of GHG emissions and economic indicators related to emissions (CARB 2020). Indicators in support of the UN's sustainable development goals were described by Schmidt-Traub et al. (2015) and include indicators designed to measure progress towards achieving climate goals, such as energy efficiency and decarbonization strategies as well as quantifying emissions from industry, transportation, and agriculture.

Emission inventories are constructed by use of economic activity factors (e.g., number of gas wells, power plants, cows) combined with emission factors (emissions per unit emitter). This kind of approach is known as a "bottom-up" approach, and an updated discussion of how inventories are developed is given by Birdsey et al. (2018). Emission estimates are often produced on a country-wide basis and reported to the UNFCCC for use in policy decisions, although some emissions datasets are spatially disaggregated (e.g., EDGAR-Emissions Database for Global Atmospheric Research, Joint Research Center) (Olivier and JanssensMaenhout 2012; Crippa et al. 2020). Bottom-up emission datasets can have considerable uncertainties, for example, they may not capture all processes leading to emissions. Emissions of $\mathrm{CO}_{2}$ occur during combustion of fossil fuels and statistics for fossil fuel consumption are considered relatively, though not perfectly, well known. On the other hand, $\mathrm{CH}_{4}$ emissions from fossil fuels result from unintentional leakage or venting during production, storage, and transport and are much more difficult to quantify. New extraction technologies have led to increased natural gas production, focusing attention on leakage from drilling, storage, and transport of fossil fuel (e.g., Alvarez et al. 2012; Peischl et al. 2015; Pétron et al. 2014). In particular, new sources of potential leakage were identified to explain higher emissions inferred from atmospheric observations compared to those estimated using bottom-up methods. Multi-decadal time series of greenhouse gas observations are essential for evaluating emission inventories; however, it is often difficult to use atmospheric concentration to attribute emissions to particular sources. For source attribution, bottom- up inventories are needed and therefore could be considered climate indicators as well. Ideally, bottom-up inventories should be spatially disaggregated so that they can be evaluated for consistency with top-down atmospheric concentration data. Atmospheric observations and emission inventories are complementary for our understanding of the processes and activities affecting climate forcing, and for devising effective and efficient ways to mitigate them (NAS 2018).

\subsection{Carbon dioxide}

Measurements of air trapped in ice cores and ongoing analysis of modern air samples show that global atmospheric $\mathrm{CO}_{2}$ has increased from $280 \mathrm{ppm}$ (parts per million of dry air, MacFarling Meure et al. 2006) in the pre-industrial atmosphere to over $413 \mathrm{ppm}$ as of July 2020 (http://www.esrl.noaa.gov/gmd/ccgg/trends/global.html). This increase has been shown to be due to human activities, especially the burning of fossil fuels with small contributions from cement production (Tans 2009) and land use change. By burning fossil fuels, humans are accelerating the part of the natural geologic carbon cycle that transfers carbon in rocks and sediments to the atmosphere, processes with timescales of ten to hundreds of millennia. Since 1870, cumulative emissions of $\mathrm{CO}_{2}$ have totaled $440 \pm 20 \mathrm{PgC}$ (Friedlingstein et al. 2019), while cumulative emissions of carbon from land use change since 1750 have been estimated at $205 \pm 60 \mathrm{PgC}$ (Friedlingstein et al. 2019). Roughly half of anthropogenic emissions remain in the atmosphere with the remainder taken up by the oceans and natural terrestrial biosphere (Ciais et al. 2013). As of 2019, $\mathrm{CO}_{2}$ accounts for $2 / 3(2.076$ $\mathrm{Wm}^{-2}$ out of $3.140 \mathrm{Wm}^{-2}$ ) of the total anthropogenic climate forcing from long-lived gases 
(not including ozone, aerosols, and clouds) (Hofmann et al. 2006 updated at http://www.esrl. noaa.gov/gmd/aggi/).

\subsection{Methane}

Current $\mathrm{CH}_{4}$ abundance in the atmosphere is unprecedented over at least the last 800,000 years (Loulergue et al. 2008), increasing by $160 \%$ since preindustrial times. Atmospheric network observations (mainly NOAA and the AGAGE network) show that global $\mathrm{CH}_{4}$ increased rapidly until the late 1990 s, leveled off during the early 2000 s, and has begun to increase rapidly again since 2006 (Rigby et al. 2008; Dlugokencky et al. 2009). The cause of the renewed atmospheric increase is currently not well understood.

Estimates reported by Saunois et al. (2020) and Jackson et al. (2020) for anthropogenic emissions are $357 \mathrm{TgCH}_{4}$ year $^{-1}$ (range 334-392 $\mathrm{TgCH}_{4}$ year $^{-1}$ ) for 2008-2017. Production of fossil fuels account for 30-35\% of all anthropogenic emissions. Livestock, agriculture, and landfills and sewage account for another $\sim 60 \%$, with the remainder due to biomass and biofuel burning. A recent study suggested that emissions from fossil fuels and geologic emissions may be $20-60 \%$ higher than previously thought, requiring compensating reduction in microbial anthropogenic emissions (Schwietzke et al. 2016) in order to match observed global average $\mathrm{CH}_{4}$ abundance and its growth. Natural emissions, mainly from wetlands and terrestrial aquatic systems, are thought to make up $\sim 40 \%$ of global emissions. $\mathrm{CH}_{4}$ has an atmospheric chemical sink that is in approximate balance with its sources, reaction with the hydroxyl radical $(\mathrm{OH})$. All sinks, including small contributions from other reactions and a microbial soil sink, result in about a 10-year atmospheric lifetime of $\mathrm{CH}_{4}$. $\mathrm{OH}$ has an extremely short atmospheric residence time and is difficult to directly measure. Its global abundance is usually inferred using observations of methyl chloroform $\left(\mathrm{CH}_{3} \mathrm{CCl}_{3}\right)$, an anthropogenic gas for which emissions are thought to be well known and for which reaction with $\mathrm{OH}$ is the main atmospheric loss (e.g., Krol and Lelieveld 2003; Montzka et al. 2011).

$\mathrm{CH}_{4}$ contributed $0.52 \mathrm{Wm}^{-2}$ in 2019 to global total anthropogenic radiative forcing, about a quarter of that due to $\mathrm{CO}_{2}$ (Hofmann et al. 2006 updated at http://www.esrl.noaa.gov/gmd/ aggi/). Including carbon cycle-climate feedbacks, the global warming potential (GWP100) of $\mathrm{CH}_{4}$ is 34; on a per mass basis, its emissions are 34 times more effective at trapping heat in the climate system than an equivalent emission of $\mathrm{CO}_{2}$ over a 100-year time horizon (Myhre et al. 2013). Due to its atmospheric lifetime of about a decade, $\mathrm{CH}_{4}$ has a significantly higher GWP20 (GWP over a 20-year time horizon) of 70. Global temperature change potential (GTP; Shine et al. 2005) is metric comparing the change in surface temperature due to emission pulses of non- $\mathrm{CO}_{2} \mathrm{GHG}$ and $\mathrm{CO}_{2}$. This metric captures the relative impact of a non- $\mathrm{CO}_{2}$ GHG at a particular time usually chosen for policy relevance. The GTP of $\mathrm{CH}_{4}$ for 20- and 100-year horizons (including carbon cycle climate feedbacks) is 70 and 11 (Myhre et al. 2013).

\subsection{Nitrous oxide}

The atmospheric budget of nitrous oxide $\left(\mathrm{N}_{2} \mathrm{O}\right)$ is not well understood, and its abundance in the atmosphere is growing at a rate of $0.94 \mathrm{ppb}$ year $^{-1}$ (Dlugokencky, NOAA/GML, www. esrl.noaa.gov/gmd/ccgg/trends_n2o). With an atmospheric lifetime of $\sim 120$ years (Davidson and Kanter 2014), it is destroyed mainly in the stratosphere by reaction with excited state atomic oxygen and photolysis. Global natural emissions (ocean upwelling and soil emissions) are thought to be 10-12 $\mathrm{Tg} \mathrm{N}_{2} \mathrm{O}-\mathrm{N}$ year ${ }^{-1}$ (Davidson and Kanter 2014). 
Anthropogenic emissions are estimated at $5.2-5.5 \mathrm{TgN}_{2} \mathrm{O}-\mathrm{N}$ year ${ }^{-1}$. About $66 \%$ of this is likely due to agriculture, mostly not only from use of industrially produced fertilizer but also from cultivation of nitrogen-fixing crops (Röckmann and Levin 2005; Park et al. 2012). Another $15 \%$ of total emissions come from fossil fuel combustion. Biomass burning contributes $11 \%$ of global emissions, with remaining emissions coming from other sources such as waste waters. Population growth nearly guarantees that $\mathrm{N}_{2} \mathrm{O}$ will continue to increase in the atmosphere since producing enough food to feed the growing human population will rely on fertilizer use (Hansen et al. 2017).

$\mathrm{N}_{2} \mathrm{O}$ has a GWP100 of 298 and an atmospheric lifetime of $\sim 120$ years (Davidson and Kanter 2014). In 2019, $\mathrm{N}_{2} \mathrm{O}$ contributed $0.2 \mathrm{Wm}^{-2}$ to global anthropogenic radiative forcing, about a tenth of that due to $\mathrm{CO}_{2}$ (Hofmann et al. 2006, updated at http://www.esrl.noaa.gov/ gmd/aggi/). The GWP20 of $\mathrm{N}_{2} \mathrm{O}$ is relatively close to its GWP100, 268. In terms of global temperature change potential, for $\mathrm{N}_{2} \mathrm{O}$, GTP100 is 297 and GTP20 is 284. Note that in comparison to $\mathrm{CH}_{4}$, the variation among these metrics is small, a reflection of the long atmospheric $\mathrm{N}_{2} \mathrm{O}$ lifetime.

\subsection{Halocarbons}

Halogenated gases have been produced by industry in significant quantities since the midtwentieth century to meet societal needs for refrigeration, air conditioning, insulation, solvents and fire protection. Measurements of air extracted from snow in Antarctica confirm that most of these halogenated chemicals (chlorofluorocarbons, hydrochlorofluorocarbons, hydrofluorocarbons, halons, and some chlorinated gases) were not present in the atmosphere in appreciable quantities before the mid-twentieth century.

Many industrially produced halogenated gases are resistant to destruction by natural processes. Once these chemicals escape from refrigerators or foams to the atmosphere, they persist for decades to centuries. They are powerful GHGs, with GWP100s that are up to 14,000 times larger than $\mathrm{CO}_{2}$. Atmospheric concentrations of halogenated gases are much lower (by $10^{6}$ ) than that of $\mathrm{CO}_{2}$, so their contribution to climate forcing today is only about $17 \%$ as large as that from $\mathrm{CO}_{2}$.

The main means by which halocarbons are destroyed and removed from the atmosphere is by photolysis in the stratosphere leading to reactive forms of chlorine and bromine that deplete stratospheric ozone. This realization led to the 1987 Montreal Protocol on Substances that Deplete the Ozone Layer, and phase-out in the global production of these chemicals. Because halocarbons are also strong GHGs, the Montreal Protocol has been the most successful global climate treaty to date (Velders et al. 2007). Future warming from these compounds will depend on the effectiveness of controls on the next generation of substitutes for ozone-depleting compounds, namely the HFCs. The Kigali Amendment to the Montreal Protocol was agreed to in late 2016 to phase down and stabilize HFC use and associated climate warming but has not yet been ratified by all parties.

\section{The annual greenhouse gas index}

The effect of anthropogenic GHGs on the energy budget of the climate system is quantified using the concept of radiative forcing. The change in radiative forcing over time is a useful climate indicator because it is directly related to the surface temperature change. 
Radiative forcing is defined as the change in net radiative flux (downward minus upward in $\mathrm{Wm}^{-2}$ ) at the tropopause due to a perturbation from an external driver, after allowing the stratosphere to come to radiative-dynamical equilibrium (Myhre et al. 2013). Radiative forcing is usually defined relative to 1750 , the start of the industrial era. A net positive change results in warming of the climate system. External perturbations include atmospheric concentration changes due to anthropogenic emissions of greenhouse gases, changes in aerosols, and changes in albedo due to land use change. Clouds and water vapor are considered internal to the climate system, but changes in atmospheric temperature and relative humidity, possibly driven by changes in atmospheric composition, can affect cloudiness.

Changes in long-lived, well mixed greenhouse gases, such as $\mathrm{CO}_{2}, \mathrm{CH}_{4}, \mathrm{~N}_{2} \mathrm{O}$, and halogenated compounds such as CFCs make up the largest and most certain component of radiative forcing, because their concentrations and atmospheric growth rates can be accurately measured in the atmosphere. The effects of anthropogenic emissions on trace gas atmospheric concentrations and radiative forcing is also relatively well understood in comparison to, for example, the radiative forcing contribution from changing cloudiness and associated cloudclimate feedbacks.

An example of a radiative forcing climate indicator is the NOAA Annual Greenhouse Gas Index (AGGI), which uses long-term global observations of important greenhouse gases to calculate changes in radiative forcing relative to 1990 (the baseline year for the Kyoto Protocol). Total radiative forcing from these main greenhouse gases is calculated using IPCC-recommended expressions derived from atmospheric radiative transfer models to convert greenhouse gas concentration increases relative to 1750 to instantaneous radiative forcing (Ramaswamy et al. 2001). Feedbacks due to water vapor and ozone depletion are not considered in this calculation because they are less well quantified. Other spatially heterogeneous, short-lived, climate forcing agents, such as aerosols and tropospheric ozone, have uncertain global magnitudes and also are not considered in the calculation of the AGGI. Changes in radiative forcing before 1978 are derived from atmospheric measurements of $\mathrm{CO}_{2}$ started in the late 1950s (Keeling 1958) and from measurements of $\mathrm{CO}_{2}$ and other greenhouse gases in air trapped in snow and ice in Antarctica and Greenland (Etheridge et al. 1996; Butler et al. 1999).

The AGGI was introduced in 2006 based on measurements through 2004 (Hofmann et al. 2006) and has been updated annually. For 2019, the AGGI was 1.45, indicating that total direct radiative forcing of anthropogenic changes in long-lived greenhouse gases since 1750 has increased $45 \%$ since 1990 .

Figure 3 shows radiative forcing for major GHGs and 15 minor long-lived halogenated gases. Many of these minor gases are also ozone-depleting gases and are regulated by the Montreal Protocol. $\mathrm{CO}_{2}$ dominates the total forcing with $\mathrm{CH}_{4}$ making up half of the remaining forcing and $\mathrm{N}_{2} \mathrm{O}$ and $\mathrm{CFCs}$ accounting for most of the remainder. Five major greenhouse gases $\left(\mathrm{CO}_{2}, \mathrm{CH}_{4}, \mathrm{~N}_{2} \mathrm{O}, \mathrm{CFC}-11\right.$, and $\left.\mathrm{CFC}-12\right)$ account for about $96 \%$ of the direct radiative forcing by long-lived greenhouse gas increases since 1750 . Note that increasing atmospheric $\mathrm{CO}_{2}$ accounts for most of the growth in radiative forcing since 1990, about $80 \%$.

Had the ozone-depleting gases not been regulated by the Montreal Protocol and its amendments, it is estimated that climate forcing in 2010 would have been as much as $0.3 \mathrm{~W} \mathrm{~m}^{-2}$ greater in 2010 (Velders et al. 2007), which is more than half of the increase in radiative forcing due to $\mathrm{CO}_{2}$ alone since 1990. Of the ozone-depleting gases and their substitutes, the largest contributors to direct warming in 2019 were CFC-12, followed by CFC-11, HCFC-22, CFC-113, and HCFC-134a. 


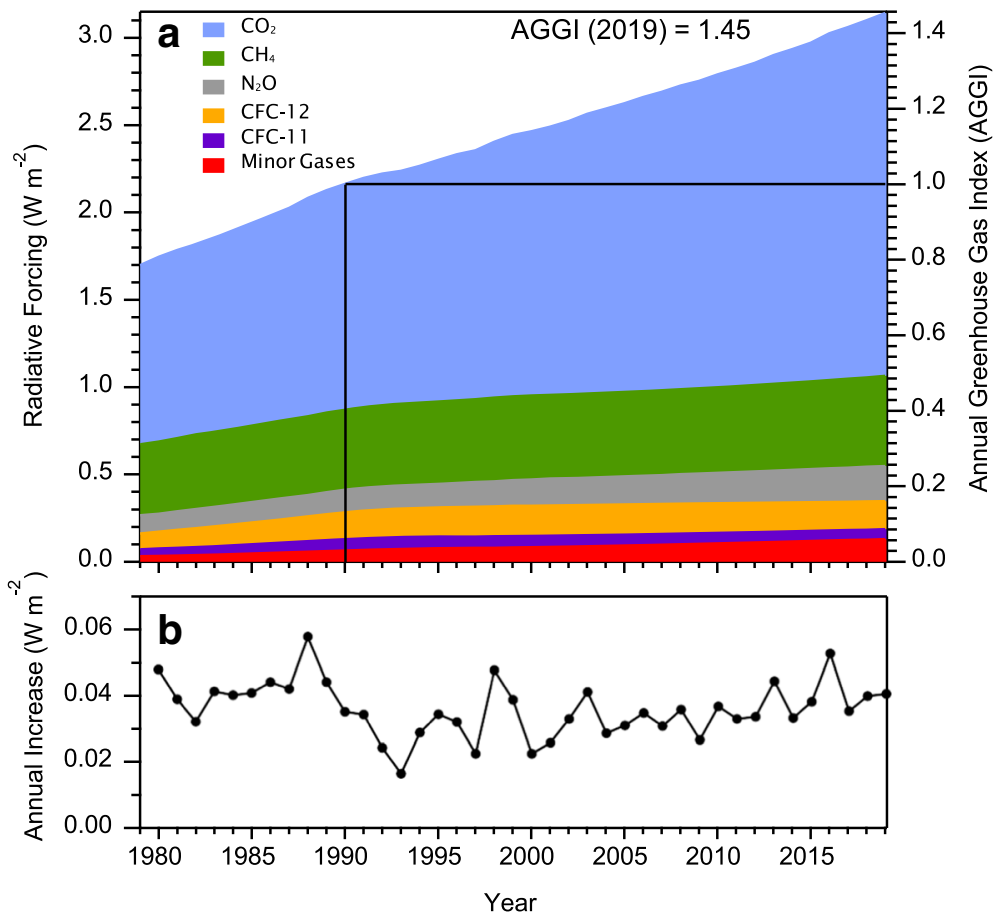

Fig. 3 Radiative forcing, relative to 1750, for long-lived greenhouse gases. The NOAA Annual Greenhouse Gas Index (AGGI), which is indexed to 1 for 1990, is shown on the right axis

\section{Potential climate indicators}

Cloud climate feedbacks are difficult to quantify, and model predictions are highly uncertain, but understanding cloud-climate feedbacks and effects on the surface radiation budget is critical for quantifying the ultimate effect of greenhouse gases on climate. A potential climate indicator is global dimming/brightening (e.g., Long et al. 2009; Wild 2012, 2009) which quantifies the change in downwelling solar radiation at the Earth's surface through time, and is an integrated function of all climate forcers and feedbacks, thus providing the highest-level constraint on radiative forcing. Long-term measurements of greenhouse gases, aerosols, and clouds and related climate indicators used with a dimming/brightening index could provide a foundation for quantifying forcing and reducing error in existing indicators that do not account for complicated cloud processes.

Earth system models (ESMs) suggest that there is a near-linear relationship between cumulative emissions of $\mathrm{CO}_{2}$ and changes in global surface air temperature (e.g., Allen et al. 2009; Gregory et al. 2009; Matthews et al. 2009). Gillet et al. (2013) showed that this emergent property from the ESMs, referred to as the transient climate response (TCRE), is consistent with both global temperature observations and estimates of cumulative emissions. The TCRE is frequently used to estimate cumulative emission limits for targeted global temperature increases. However, the slopes of the TCRE linear relationships vary among models due to differences in how carbon cycle feedbacks are represented in models (MacDougall et al. 2016; Friedlingstein et al. 2014). Observational constraints on carbon cycle feedbacks could help to constrain TCRE and lead to improvements in ESMs. 
About half of all anthropogenic $\mathrm{CO}_{2}$ emissions to date have been taken up by the oceans and terrestrial biosphere (Ciais et al. 2013). The size of this "carbon emission discount" will likely change in the future as more carbon accumulates in the oceans, as humans alter landscapes, as climate changes, and atmospheric composition continues to evolve. Efforts to limit global average temperature increases and hopefully avoid the most catastrophic consequences of climate change could be affected by how natural fluxes of carbon and nitrogen change in response to human activities and changing climate.

Coupled carbon cycle-climate models forced with scenarios for future emissions suggest that carbon cycle changes in response to anthropogenic climate change will likely be a positive (additive) feedback on climate, enhancing warming. The magnitude of the projected feedback is uncertain, and a wide range of future atmospheric carbon abundances is predicted by models (Friedlingstein et al. 2014). There are many possible processes that can result in positive carbon cycle feedbacks. A warmer climate can lead to increased fires and droughts, resulting in less uptake and storage of carbon by the terrestrial biosphere. Warming is expected to decrease carbon uptake in the tropics and mid-latitudes (a positive feedback), while in the high latitudes, a warmer climate may lead to increased productivity of the terrestrial biosphere and carbon uptake (a negative feedback), although this may be offset by increases in respiration and release of some of the vast amounts of carbon stored in soils and lakes. Increased atmospheric $\mathrm{CO}_{2}$ may cause a fertilization effect on global vegetation leading to increased carbon storage, but the importance of this effect and the factors (e.g., nutrients) which could limit it are highly uncertain.

Land use change can directly affect climate since deforestation and agriculture alter carbon storage in soils and biomass. Fertilizer use also has impacts on the global nitrogen budget and may increase carbon storage while also affecting productivity in marine and freshwater environments as it is washed into marine environments. On the other hand, increased fertilizer use can not only result in increased food production but also increased emissions of the powerful greenhouse gas, $\mathrm{N}_{2} \mathrm{O}$. Creation or drainage of wetlands can alter $\mathrm{CH}_{4}$ emissions (Kolka et al. 2018). For example, drainage of wetlands can lead to lower $\mathrm{CH}_{4}$ emissions but higher $\mathrm{CO}_{2}$ emissions as a result of lower anerobic respiration and higher aerobic respiration.

Increasing atmospheric $\mathrm{CO}_{2}$ also has implications for ocean waters (Cooley et al. 2018). As the partial pressure of $\mathrm{CO}_{2}$ in the atmosphere increases, ocean carbon increases and waters become more acidic. Eventually, ocean waters may acidify enough to dissolve calcium carbonate $\left(\mathrm{CaCO}_{3}\right)$ shells of ocean organisms, possibly significantly perturbing ocean ecosystems and reducing productivity of ocean waters.

Frozen Arctic soils are another potentially important carbon cycle-climate feedback (Schuur et al. 2018). An estimated $1700 \mathrm{PgC}$ is frozen in Arctic soils, and warming has proceeded in the Arctic faster than any other region. Current understanding is that $\sim 130-160 \mathrm{PgC}$, primarily as $\mathrm{CO}_{2}$, could be released over the next century (Schuur et al. 2013). On an annual basis, Schuur et al. (2015) estimate that annual carbon releases, if at a constant rate, could be lower than annual fossil fuel emissions ( $\sim 9$ PgCyear $\left.^{-1}\right)$, but comparable to land use change $(0.9$ PgCyear-1). A small percentage of Arctic soil carbon could be released as $\mathrm{CH}_{4}$, a more powerful greenhouse gas.

Understanding and identifying feedbacks between GHGs and climate, such as those mentioned above, at a variety of spatial and temporal scales is of first-order importance (Huntzinger et al. 2018). The ability to supply food to a growing global population could be threatened by changes in productivity of marine and land ecosystems. Efforts to reduce GHG emissions could also be made significantly less effective by carbon cycle feedbacks. 
Disentangling changes in atmospheric composition that are due to human activities from those due to natural processes is a fundamental scientific challenge. Many GHGs are such as the $\mathrm{CFCs}_{2}, \mathrm{SF}_{6}$, and other halocarbons, are manufactured and do not occur in nature, unlike $\mathrm{CO}_{2}, \mathrm{CH}_{4}$, and $\mathrm{N}_{2} \mathrm{O}$ which have complex sources and sinks that overlap in space and time. GHGs can have removal processes that vary over time, and accounting for these changes is also important when quantitatively estimating the change in radiative forcing due to emissions, especially for short-lived species.

A potential climate indicator that could be useful for tracking anthropogenic $\mathrm{CO}_{2}$ emissions was introduced by Hofmann et al. (2006), who estimated the anthropogenic contribution to observed global average $\mathrm{CO}_{2}$ mole fraction by subtracting the pre-industrial value of $280 \mathrm{ppm}$. They noted that the resulting anthropogenic $\mathrm{CO}_{2}$ mole fraction could be fit to an exponential function with a doubling time of approximately 30 years, and suggested that this doubling time is linked with global population growth. Figure 4 shows an extension of the Hofmann et al. (2009) analysis for recent years using identical fit parameters. A clear trend away from the exponential growth curve can be seen after 2008 implying that growth in anthropogenic $\mathrm{CO}_{2}$ is decelerating, possibly due to increased energy efficiency and slower economic growth for these years. Note that in 2015 and 2016, there was an uptick in $\mathrm{CO}_{2}$ that is likely related to a strong El Niño that caused a net release of carbon from the terrestrial biosphere as well as economic growth. While this event illustrates the difficulty in separating anthropogenic and natural signals over short time periods as well as further disentangling the response of the land and the ocean components (Chatterjee et al. 2017), longer-term changes are driven almost exclusively by human activities (Tans 2009). It would clearly be ideal to be able to subtract a natural signal from the curves shown in Fig. 4; however, doing so requires either conclusions drawn from uncertain terrestrial and ocean carbon exchange models, or additional observational information.

Observations of trace species with budgets that are related to major GHGs can be helpful for discriminating between anthropogenic and natural contributions. For example, measurements of $\delta^{13} \mathrm{C}\left(\mathrm{CH}_{4}\right)$ can be useful for partitioning emissions between thermogenic (fossil fuels and natural geologic sources) and natural and anthropogenic microbial sources (Schaefer et al. 2016; Nisbet et al. 2016). Radiocarbon $\left({ }^{14} \mathrm{CO}_{2}\right.$ and $\left.{ }^{14} \mathrm{CH}_{4}\right)$ can be useful for identifying fossil fuel emissions since all of the ${ }^{14} \mathrm{C}$ in fossils fuels has decayed away over the millions of years it took to transform organic to fossil carbon (Graven 2015; Basu et al. 2020). Ethane $\left(\mathrm{C}_{2} \mathrm{H}_{6}\right)$ and other hydrocarbons can in theory be used to constrain $\mathrm{CH}_{4}$ emissions from oil and gas production; however, the emission ratios must be well characterized over space and time (Peischl et al. 2015; Peischl et al. 2016). In addition, COS has been used to constrain uptake of $\mathrm{CO}_{2}$ as a result of photosynthesis (Montzka et al. 2007). The use of measurements of related species to constrain GHG budgets is currently an active area of research that may lead to additional robust climate indicators.

\subsection{Using remote sensing to monitor atmospheric composition}

In situ observational approaches allow for high-quality measurements of atmospheric composition; however, they are limited in spatial and temporal coverage. Over the past decade, remote sensing of atmospheric constituents from satellites has emerged as a potential new technique to quantify the time evolution of atmospheric GHGs. Retrievals of column average abundances from remote sensors use emission or absorption spectra at the top of the atmosphere (TOA). Early GHG satellite instruments such as the Atmospheric Infrared Sounder (AIRS) and the Thermal Emission Sounder (TES) were primarily built for estimating air 


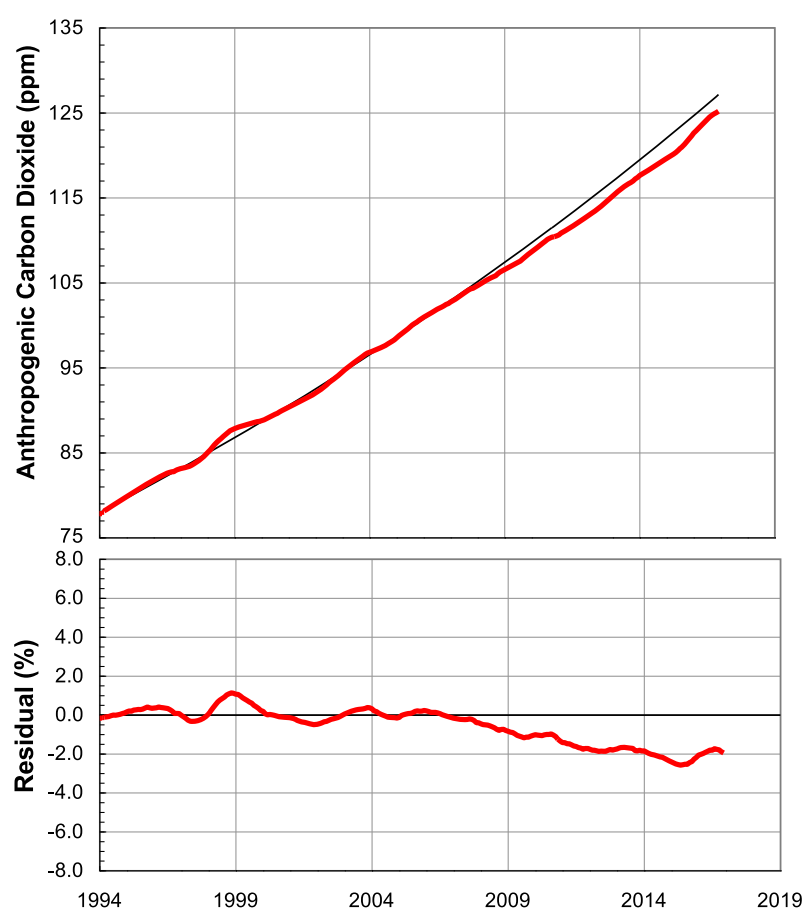

Fig. 4 (Top) De-seasonalized global average anthropogenic $\mathrm{CO}_{2}$ (red), estimated by subtracting the preindustrial value of $280 \mathrm{ppm}$. The black curve shows an exponential fit to observations using the fit parameters of Hofmann et al. (2009) that results in an emission doubling time of about 30 years. (Bottom) The difference between the exponential fit of Hofmann et al. (2009) and observed global average $\mathrm{CO}_{2}$

temperature and water vapor content, and GHG retrievals were incidental benefits from having TOA thermal infrared spectra. The resulting GHG estimates were primarily of the upper troposphere and stratosphere, which are inadequate for estimating surface fluxes.

Satellites such as SCanning Imaging Absorption SpectroMeter for Atmospheric CHartographY (SCIAMACHY), Greenhouse Gases Observing Satellite (GOSAT), TROPOspheric Monitoring Instrument (TROPOMI), and Orbiting Carbon Observatory (OCO) have been built specifically for estimating GHG mole fractions from space. These satellites are sensitive to short wave infrared (SWIR) radiation of sunlight reflected from the Earth's surface, and provide estimates of the vertical column average $\mathrm{CO}_{2}$ and $\mathrm{CH}_{4}$ mole fraction including significant sensitivity to the lower troposphere. More such observing systems are planned for the near future, including the Geostationary Carbon Observatory (GeoCARB), MicroCarb, GOSAT-2, and CarbonSat. In theory, GHG estimates from these satellites could be used to track near-surface GHG mole fractions and thereby estimate surface processes behind their fluxes, including their response to climate variability. In practice, the accuracy requirements on satellite sensors of GHGs are daunting, since the signal in the total column that they need to detect is an order of magnitude smaller than the near-surface signal. As a result, small biases $\left(\sim 0.5 \mathrm{ppm}\right.$ for $\mathrm{CO}_{2}$ and 1-2 ppb for $\left.\mathrm{CH}_{4}\right)$ in total column estimates can significantly alter the inferred surface fluxes of the respective species and skew conclusions about their climate response. Current estimates of $\mathrm{CO}_{2}$ and $\mathrm{CH}_{4}$ from existing satellite instruments have spatially coherent biases which make it challenging to use them to track carbon climate feedbacks. However, significant progress has been made in this area over the past decade, and it is 
possible that over the next decade these biases will be further reduced to acceptable levels. Commercial and non-governmental organizations are also developing space-based observing systems with very high spatial resolution (1 km or less) for detecting methane leaks, especially from oil and gas operations (Crisp et al. 2018, App. 5). Examples include GHGSat, MethaneSAT, and microsatellites planned by Bluefield Technologies. Observing systems such as these could provide essential improvements to our ability to quantify fugitive emissions of $\mathrm{CH}_{4}$ from anthropogenic sources.

\section{Conclusions}

We propose that long-term observations of atmospheric greenhouse gases be considered as climate indicators, and we have presented a conceptual model showing the relationship between emissions, fluxes, concentration, and radiative forcing. Knowledge of the GHG atmospheric abundances and their change over time allows us to compute and track the associated radiative forcing, as is being done with the Annual Greenhouse Gas Index, for example. GHG abundances and their changes over time also provide valuable information on the success of climate mitigation policies and insights into possible carbon-climate feedback processes that may change the effectiveness of those policies. To ensure that reliable information for assessing GHG emission changes can be provided at need spatial and temporal scales, expanded observational efforts are needed. Furthermore, the ability to detect trends resulting from changing emissions requires a commitment to supporting long-term observations. Efforts to improve and continue bottom-up techniques are also be needed since the interplay of bottom-up and top-down approaches is vital to the success of understanding and mitigating climate change.

Acknowledgements Data used in this study were collected by the NOAA Global Monitoring Laboratory which supported the work of Bruhwiler, Dlugokencky, Montzka, Butler, and Stanitski.

Author contribution All authors contributed to the development of this paper by contributing text. The paper concept was developed by Kenney, Butler, and Stanitski. The original draft was prepared by Bruhwiler.

Funding Bruhwiler, Butler, Montzka, Dlugencky, and Stanitski are employed by the NOAA Global Monitoring Laboratory. The work of Chatterjee was supported by funding from the NASA Grant/Cooperative Agreement NNX17AD69A and 80NSSC20K0006. Kenney was supported by the National Oceanic and Atmospheric Administration grants NA09NES4400006 and NA14NES4320003 (Cooperative Climate and Satellites-CICS) at the University of Maryland/ESSIC.

Data availability All data used in this study are freely available for download from https://www.esrl.noaa.gov/ gmd/.

\section{Declarations}

Conflict of interest The authors declare no competing interests.

Open Access This article is licensed under a Creative Commons Attribution 4.0 International License, which permits use, sharing, adaptation, distribution and reproduction in any medium or format, as long as you give appropriate credit to the original author(s) and the source, provide a link to the Creative Commons licence, and indicate if changes were made. The images or other third party material in this article are included in the article's Creative Commons licence, unless indicated otherwise in a credit line to the material. If material is not included in the article's Creative Commons licence and your intended use is not permitted by statutory regulation or 
exceeds the permitted use, you will need to obtain permission directly from the copyright holder. To view a copy of this licence, visit http://creativecommons.org/licenses/by/4.0/.

\section{References}

Allen MR, Frame DJ, Huntingford C, Jones CD, Lowe JA, Meinshausen M, Meinshausen N (2009) Warming caused by cumulative carbon emissions towards the trillionth tonne. Nature, 458(7242):1163-6. https://doi. org/10.1038/nature08019.PMID:19407800

Allen M. R. et al. (2018) Framing and context. in "Global warming of $1.5^{\circ} \mathrm{C}$. An IPCC Special Report on the impacts of global warming of $1.5^{\circ} \mathrm{C}$ above pre-industrial levels and related global greenhouse gas emission pathways, in the context of strengthening the global response to the threat of climate change, sustainable development, and efforts to eradicate poverty." (IPCC).

Alvarez AR, Pacala SW, Winebrake JJ, Chameides WL, Hamburg SP (2012) Greater focus needed on methane leakage from natural gas infrastructure. PNAS 109(17):6435-6440. https://doi.org/10.1073/pnas. 1202407109

Basu S, Lehman SJ, Miller JB, Andrews AE, Sweeney C, Gurney KR, Xu X, Southon J, Tans PP (2020) Estimating US fossil fuel $\mathrm{CO}_{2}$ emissions from measurements of ${ }^{14} \mathrm{CO}_{2}$ in atmospheric $\mathrm{CO}_{2}$. PNAS 117(24): 13300-13,307. https://doi.org/10.1073/pnas.1919032117

Birdsey R, Gurwick NP, Gurney KR, Shrestha G, Mayes MA, Najjar RG, Reed SC, Romero-Lankao P (2018) Appendix D. Carbon measurement approaches and accounting frameworks. In: Cavallaro N, Shrestha G, Birdsey R, Mayes MA, Najjar RG, Reed SC, Romero-Lankao P, Zhu Z (eds) Second State of the Carbon Cycle Report (SOCCR2): a sustained assessment report. U.S. Global Change Research Program, Washington, DC, pp 834-838. https://doi.org/10.7930/SOCCR2.2018.AppD

Buizer, J. L., P. Fleming, S. L. Hays, K. Dow, C. B. Field, D. Gustafson, A. Luers, and R. H. Moss (2013) Preparing the nation for change: building a sustained national climate assessment process. National Climate Assessment and Development Advisory Committee (NCADAC) Rep., 73 pp., https://sncaadvisorycommittee.noaa.gov/Portals/0/Meeting-Documents/NCA-SASRWG_Report_Print.pdf.

Butler J, Battle M, Bender M et al. (1999) A record of atmospheric halocarbons during the twentieth century from polar firn air. Nature 399:749-755. https://doi.org/10.1038/21586

California Air Resources Board (CARB) (2020) California greenhouse gas emissions for 2000 to 2018, trends of emissions and other indicators, https://ww3.arb.ca.gov/cc/inventory/pubs/reports/2000_2018/ghg_ inventory_trends_00-18.pdf

Canadell JG, Ciais P, Dhakal S et al (2010) Interactions of the carbon cycle, human activity and the climate system: a research portfolio. Curr Opin Environ Sustain 2:301-311

Cain M, Lynch J, Allen MR et al (2019) Improved calculation of warming-equivalent emissions for short-lived climate pollutants. npj Clim Atmos Sci 2:29. https://doi.org/10.1038/s41612-019-0086-4

Chatterjee A, Gierach MM, Sutton AJ, Feely RA, Crisp D, Eldering A, Gunson MR, O’Dell CW, Stephens BB, Schimel DS (2017) Influence of El Niño on atmospheric $\mathrm{CO}_{2}$ over the tropical Pacific Ocean: findings from NASA's OCO-2 mission. Science 358:6360, eaam5776. https://doi.org/10.1126/science.aam5776

Ciais P, Sabine C, Bala G et al (2013) Carbon and other biogeochemical cycles. In: Stocker TF, Qin D, Plattner G-K, Tignor M, Allen SK, Boschung J, Nauels A, Xia Y, Bex V, Midgley PM (eds) Climate change 2013: the physical science basis. Contribution of Working Group I to the Fifth Assessment Report of the Intergovernmental Panel on Climate Change. Cambridge University Press, Cambridge, United Kingdom and New York, NY, USA

Collins WJ, Frame DJ, Fuglestvedt JS, Shine KP (2020) Environ. Res Lett 15:024018. https://oi.org/10.1088/ 1748-9326/ab6039

Cooley SR, Moore DJP, Alin SR et al (2018) Chapter 17: Biogeochemical effects of rising atmospheric carbon dioxide. In Second State of the Carbon Cycle Report (SOCCR2): a sustained assessment report. In: Cavallaro N, Shrestha G, Birdsey R, Mayes MA, Najjar RG, Reed SC, Romero-Lankao P, Zhu Z (eds) . U.S. Global Change Research Program, Washington, DC, pp 690-727. https://doi.org/10.7930/SOCCR2.2018.Ch17

Corell RW, Liverman D, Dow K, Ebi KL, Kunkel K, Mearns LO, Melillo J (2014) Ch. 29: Research needs for climate and global change assessments. In: Melillo JM, Richmond T, Yohe GW (eds) Climate Change Impacts in the United States: The Third National Climate Assessment. U.S. Global Change Research Program, pp 707-718. https://doi.org/10.7930/J03R0QR3

Cowtan K, Hausfather Z, Hawkins E, Jacobs P, Mann ME, Miller SK et al (2015) Robust comparison of climate models with observations using blended land air and ocean sea surface temperatures. Geophys Res Lett 42: 6526-6534. https://doi.org/10.1002/2015GL064888 
Crippa M, Solazzo E, Huang G et al (2020) High resolution temporal profiles in the Emissions Database for Global Atmospheric Research. Sci Data 7:121. https://doi.org/10.1038/s41597-020-0462-2

Crisp, D., Y. Meijer, R. Munro et al. (2018) A constellation architecture for monitoring carbon dioxide and methane from space, Committee on Earth Observation Satellites. http://ceos.org/document_management/ Virtual_Constellations/ACC/Documents/CEOS_AC-VC_GHG_White_Paper_Publication_Draft2 20181111.pdf

Davidson EA, Kanter D (2014) Inventories and scenarios of nitrous oxide emissions. Environ Res Lett 9:105,012

Dlugokencky EJ, Bruhwiler L, White et al (2009) Observational constraints on recent increases in the atmospheric $\mathrm{CH}_{4}$ burden. Geophys Res Lett 36:L18803. https://doi.org/10.1029/2009GL039780

Etheridge DM, Steele LP, Langenfelds RL, Francey RJ (1996b) Natural and anthropogenic changes in atmospheric $\mathrm{CO}_{2}$ over the last 1000 years from air in Antarctic ice and firn. J Geophys Res 101:4115-4128

Friedlingstein P, Jones MW, O’Sullivan et al (2019) Global carbon budget 2019. Earth Syst Sci Data 11:17831838. https://doi.org/10.5194/essd-11-1783-2019

Friedlingstein P, Meinshausen M, Arora VK, Jones CD, Anav A, Liddicoat SK, Knutti R (2014) Uncertainties in CMIP5 climate projections due to carbon cycle feedbacks. J Clim 27(2):511-526. https://doi.org/10.1175/ JCLI-D-12-00579.1

Gillett NP, Arora VK, Matthews D, Allen MR (2013) Constraining the ratio of global warming to cumulative CO emissions using CMIP5 simulations. J Clim 26(18):6844-6858. https://doi.org/10.1175/JCLI-D-12-00476.1

Graven HD (2015) Impact of fossil fuel emissions on radiocarbon. PNAS 112(31):9542-9545. https://doi.org/10. 1073/pnas.1504467112

Gregory JM, Jones CD, Cadule P, Friedlingstein P (2009) Quantifying carbon cycle feedbacks. J Clim 22(19): 5232-5250. https://doi.org/10.1175/2009JCLI2949.1

Hansen J, Sato M, Kharecha P et al (2017) Young people's burden: requirement of negative $\mathrm{CO}_{2}$ emissions. Earth Syst Dyn 8:577-616. https://doi.org/10.5194/esd-8-577-2017

Hofmann DJ, Butler JH, Conway TJ, Dlugokencky EJ, Elkins JW, Masarie K, Montzka SA, Schnell RC, Tans PP (2006) Tracking climate forcing: the Annual Greenhouse Gas Index. EOS Trans Am Geophys Union 87: 46. https://doi.org/10.1029/2006EO460002

Hofmann, DJ, Butler JH, Tans PP (2009) A new look at atmospheric carbon dioxide, Atmos. Env. 43(12):2084 2086. https://doi.org/10.1016/jatmosenv.2008.12.028

Huntzinger DN, Chatterjee A, Moore DJP et al (2018) Chapter 19: Future of the North American carbon cycle. In: Cavallaro N, Shrestha G, Birdsey R, Mayes MA, Najjar RG, Reed SC, Romero-Lankao P, Zhu Z (eds) Second State of the Carbon Cycle Report (SOCCR2): a sustained assessment report. U.S. Global Change Research Program, Washington, DC, pp 760-809. https://doi.org/10.7930/SOCCR2.2018.Ch19

Jackson RB, Saunois M, Bousquet P, Canadell JG, Poulter B, Stavert AR, Bergamaschi P, Niwa Y, Segers A, Tsuruta A (2020) Environ Res Lett 15:071,002. https://doi.org/10.1088/1748-9326/ab9ed2

Jenkins S, Millar RJ, Leach N, Allen MR (2018) Framing climate goals in terms of cumulative $\mathrm{CO}_{2}$-forcingequivalent emissions. Geophys Res Lett 45:2795-2804. https://doi.org/10.1002/2017GL076173

Keeling CD (1958) The concentration and isotopic abundances of atmospheric carbon dioxide in rural areas. Geochim Cosmochim Acta 13:322-334

Kenney, M.A., Janetos, A.C. \& Gerst, M.D. (2018) A framework for national climate indicators. Clim Chang. https://doi.org/10.1007/s10584-018-2307-y

Kenney MA, Janetos AC, Lough GC (2016) Building an integrated U.S. National Climate Indicators System. In: Jacobs K, Moser S, Buizer J (eds) The US National Climate Assessment. Springer Climate. Springer, Cham. https://doi.org/10.1007/978-3-319-41802-5_7

Kenney MA, Janetos AC et al. (2014) National climate indicators system report. National Climate Assessment Development and Advisory Committee.

Kolka R, Trettin C, Tang W et al (2018) Chapter 13: Terrestrial wetlands. In: Cavallaro N, Shrestha G, Birdsey R, Mayes MA, Najjar RG, Reed SC, Romero-Lankao P, Zhu Z (eds) Second State of the Carbon Cycle Report (SOCCR2): a sustained assessment report. U.S. Global Change Research Program, Washington, DC, pp 507-567. https://doi.org/10.7930/SOCCR2.2018.Ch13

Krol M, Lelieveld J (2003) Can the variability in tropospheric $\mathrm{OH}$ be deduced from measurements of 1,1,1trichloroethane (methyl chloroform)? J Geophys Res 108:D3. https://doi.org/10.1029/2002JD002423

Long CN, Dutton EG, Augustine JA, Wiscombe W, Wild M, McFarlane SA, Flynn CJ (2009) Significant decadal brightening of downwelling shortwave in the continental United States. J Geophys Res 114: D00D06. https://doi.org/10.1029/2008JD011263

Loulergue L, Schilt A, Spahni R, Masson-Delmotte V, Blunier T, Lemieux B, Barnola J-M, Raynaud D, Stocker TF, Chappellaz J (2008) Orbital and millennial-scale features of atmospheric $\mathrm{CH}_{4}$ over the past 800 , 000 years. Nature 453:383-386. https://doi.org/10.1038/nature06950

MacDougall AH (2016) The transient reponse to cumulative CO emissions: a review. Curr Clim Change Rep 2: 39-47. https://doi.org/10.1007/s40641-015-0030-6 
MacFarling Meure C, Etheridge D, Trudinger C, Steele P, Langenfelds R, van Ommen T, Smith A, Elkins J (2006) Law dome $\mathrm{CO}_{2}, \mathrm{CH}_{4}$ and $\mathrm{N}_{2} \mathrm{O}$ ice core records extended to 2000 years BP. Geophys Res Lett 33: L14810. https://doi.org/10.1029/2006GL026152

Matthews HD, Gillett NP, Stott PA, Zickfeld K (2009) The proportionality of global warming to cumulative carbon emissions. Nature 459(7248):829-832. https://doi.org/10.1038/nature08047

Montzka SA, Krol M, Dlugokencky E, Hall B, Jockel P, Lelieveld J (2011) Small interannual variability of global atmospheric hydroxyl. Science. 331(6013):67-69. https://doi.org/10.1126/science.1197640

Montzka SA, Calvert P, Hall BD, Elkins JW, Conway TJ, Tans PP, Sweeney C (2007) On the global distribution, seasonality, and budget of atmospheric carbonyl sulfide (COS) and some similarities to $\mathrm{CO}_{2}$. J Geophys Res Atmos 112:D09302. https://doi.org/10.1029/2006JD007665

Myhre G, Shindell D, Bréon F-M et al (2013) Anthropogenic and natural radiative forcing. In: Stocker TF, Qin D, Plattner G-K et al (eds) Climate change 2013: the physical science basis. Contribution of Working Group I to the Fifth Assessment Report of the Intergovernmental Panel on Climate Change. Cambridge University Press, Cambridge, United Kingdom and New York, NY, USA

National Academies of Sciences, Engineering, and Medicine (NAS) (2018) Improving the characterization of anthropogenic methane emissions in the United States. The National Academies Press, Washington, D.C. https://doi.org/10.17226/24987

Nisbet EG, Dlugokencky EJ, Manning et al (2016) Rising atmospheric methane: 2007-2014 growth and isotopic shift. Glob Biogeochem Cycles 30(9):1356-1370. https://doi.org/10.1002/2016GB005406

Olivier, J.G.J. and G. Janssens-Maenhout (2012) http://edgar.jrc.ec.europa.eu/docs/IEA_PARTIII.pdf.

Park S, Croteau P, Boering K, et al. (2012) Trends and seasonal cycles in the isotopic composition of nitrous oxide since 1940. Nature Geosci 5:261-265. https://doi.org/10.1038//ngeo1421

Peischl J, Karion A, Sweeney C et al (2016) Quantifying atmospheric methane emissions from oil and natural gas production in the Bakken shale region of North Dakota. J Geophys Res Atmos 121:6101-6111. https://doi. org/10.1002/2015JD024631

Peischl, J., Ryerson, T.B., Aikin, et al. (2015) Quantifying atmospheric methane emissions from the Haynesville, Fayetteville, and northeastern Marcellus shale gas production regions. J Geophys Res Atmos 120: 21192139. https://doi.org/10.1002/2014JD022697

Pétron G et al (2014) A new look at methane and nonmethane hydrocarbon emissions from oil and natural gas operations in the Colorado Denver-Julesburg Basin. J Geophys Res Atmos 119:6836-6852. https://oi.org/ 10.1002/2013JD021272

Ramaswamy et al (2001) Radiative forcing of climate change, Chapter 1 in climate change 2001: the scientific basis. Cambridge Univ. Press, Cambridge UK and New York, NY USA

Richardson M, Cowtan K, Millar RJ (2018) Global temperature definition affects achievement of long-term climate goals. Environ Res Lett 13:54,004

Rigby M, Mühle J, Miller BR et al (2010) History of atmospheric $\mathrm{SF}_{6}$ from 1973 to 2008. Atmos Chem Phys 10: 10,305-10,320. https://doi.org/10.5194/acp-10-10,305-2010

Rigby M, Prinn RG, Fraser et al (2008) Renewed growth of atmospheric methane. Geophys Res Lett 35:L22805. https://doi.org/10.1029/2008g1036037

Röckmann T, Levin I (2005) High-precision determination of the changing isotopic composition of atmospheric $\mathrm{N}_{2} \mathrm{O}$ from 1990 to 2002. J Geophys Res 110(D21304)

Saunois M, Stavert AR, Poulter B et al (2020) The global methane budget 2000-2017. Earth Syst Sci Data 12: 1561-1623. https://doi.org/10.5194/essd-12-1561-2020

Schaefer H, Mikaloff Fletcher SE, Veidt C et al (2016) A twenty-first century shift from fossil-fuel to biogenic methane emissions indicated by ${ }^{13} \mathrm{CH}_{4}$. Science. https://doi.org/10.1126/science.aad2705

Schmidt-Traub G, de la Mothe Karoubi E, Espey J (2015) Indicators and a monitoring framework for the sustainable development goals, launching a data revolution for the SDGs, a report to the Secretary General of the United Nations by the Leadership Council of the Sustainable Development Solutions Network. https:// resources.unsdsn.org/indicators-and-a-monitoring-framework-for-sustainable-development-goals-launchinga-data-revolution-for-the-sdgs

Schuur EAG, McGuire AD, Romanovsky V, Schädel C, Mack M (2018) Chapter 11: Arctic and boreal carbon. In: Cavallaro N, Shrestha G, Birdsey R, Mayes MA, Najjar RG, Reed SC, Romero-Lankao P, Zhu Z (eds) Second State of the Carbon Cycle Report (SOCCR2): a sustained assessment report. U.S. Global Change Research Program, Washington, DC, USA, pp 428-468. https://doi.org/10.7930/SOCCR2.2018.Ch11

Schuur EAG, McGuire AD, Schädel C et al (2015) Climate change and the permafrost carbon feedback. Nature 520(7546):171-179. https://doi.org/10.1038/nature14338

Schuur EAG, Abbott BW, Bowden WB, Brovkin V, Camill P et al (2013) Expert assessment of vulnerability of permafrost carbon to climate change. Clim Chang 119:359-374

Schwietzke S, Sherwood O, Bruhwiler L et al (2016) Upward revision of global fossil fuel methane emissions based on isotopic database. Nature 538:88-91. https://doi.org/10.1038/nature19797 
Shine, K.P., Fuglestvedt, J.S., Hailemariam, K. et al. (2005) Alternatives to the global warming potential for comparing climate impacts of emissions of greenhouse gases. Clim Chang 68, 281-302 (2005). https://doi. org/10.1007/s10584-005-1146-9

Tanaka K, Cavalett O, Collins WJ et al (2019) Asserting the climate benefits of the coal-to-gas shift across temporal and spatial scales. Nat Clim Chang 9:389-396. https://doi.org/10.1038/s41558-019-0457-1

Tanaka K, Peters GP, Fuglestvedt JS (2010) Policy update: multicomponent climate policy: why do emission metrics matter? Carbon Manag 1(2):191-197. https://doi.org/10.4155/cmt.10.28

Tans P (2009) An accounting of the observed increase in oceanic and atmospheric $\mathrm{CO}_{2}$ and an outlook for the future. Oceanography 22(4):26-35

Thomas C, Tennant T, Rolls J (2000) The GHG indicator: UNEP guidelines for calculating greenhouse gas emissions for businesses and non-commercial organisations, UNEP Economics and Trade Unit, Geneva, Switzerland. https://www.unepfi.org/fileadmin/documents/ghg_indicator_2000.pdf

Velders GJM, Andersen SO, Daniel JS, Fahey DW, McFarland M (2007) The importance of the Montreal Protocol in protecting climate. PNAS 104:4814 4819

Wild M (2012) Enlightening global dimming and brightening. Bull Am Meteorol Soc 93:27-37. https://doi.org/ 10.1175/BAMS-D-11-00074.1

Wild M (2009) Global dimming and brightening: a review. J Geophys Res. https://doi.org/10.1029/ 2008JD011470

Publisher's note Springer Nature remains neutral with regard to jurisdictional claims in published maps and institutional affiliations.

\section{Affiliations}

\section{Lori Bruhwiler $^{1}$ - Sourish Basu ${ }^{2,3}$ • James H. Butler ${ }^{1}$ • Abhishek Chatterjee ${ }^{2,3}$ • Ed Dlugokencky $^{1}$ • Melissa A. Kenney ${ }^{4}$ - Allison McComiskey ${ }^{5} \cdot$ Stephen A. Montzka $^{1}$ • Diane Stanitski ${ }^{1}$}

1 NOAA Global Monitoring Laboratory, Boulder, CO, USA

2 NASA Goddard Space Flight Center, Greenbelt, MD, USA

3 Universities Space Research Association, Columbia, MD, USA

4 University of Minnesota Institute on the Environment, Saint Paul, MN, USA

5 Brookhaven National Laboratory, Environmental \& Climate Sciences Department, Upton, NY, USA 